\title{
Subjetividade pós-mídia nas diferentes telas: o cinema menor na Baixada Fluminense
}

\section{POST-MEDIA SUBJECTIVITY IN THE DIFFERENT SCREENS: THE MINOR CINEMA IN BAIXADA FLUMINENSE}

\section{Alita Villas Boas Sá Rego}

Alita Sá RegoProf. Dra. Adjunta UERJ/FEBFCoordenadora do Laborav/Laboratório de Recursos Audiovisuais/UERJ-FEBFProf. do PPG Educação, Cultura e Comunicação em Periferias Urbanas. FEBF/UERJProf. Dept Fundamentos Científicos da Educação.

E-mail: alitasa.rego@gmail.com

\section{Resumo}

Este texto trata: dos processos de subjetivação decorrentes convergência tecnológica;da questão do realismo nos cinemas analógico e digital; da passagem do conceito de cinema para o de audiovisual; da caracterização do cinema menor; das práticas realizadas durante a produção de um curta-metragem de ação realizado pelos alunos de uma faculdade de educação da Baixada Fluminense. Utilizamos como metodologia os conceitos de Deleuze e Guattari, a bibliografia específica das áreas do cinema, tanto analógico quanto digital, das tecnologias de comunicação e informação e da convergência tecnológica.

Palavras chave: Inovação. Subjetividade. Cinema digital.

\section{Abstract}

This text deals with: the processes of subjectivation resulting from technological convergence; the question of realism in analog and digital cinemas; the transition from the concept of cinema to that of audiovisual; the characterization of the smaller cinema; of the practices carried out during the production of a short film of action by the students of an education college in Baixada Fluminense. We use as a methodology the concepts of Deleuze and Guattari, the specific bibliography of the areas of cinema, both analog and digital, communication and information technologies and technological convergence.

Keywords: Inovation. Subjectivity. Digital cinema. 


\section{Introdução}

Neste texto, abordaremos algumas transformações pelas quais o cinema passou, com a chegada da tecnologia digital e a produção de uma subjetividade pós-mídia que surge a partir da convergência das mídias ${ }^{1}$. Na área do cinema, a subjetividade pós-mídia se apropria das facilidades de manuseio e do barateamento de custos produzidos pela tecnologia para inventar novas formas de criar/produzir longe das grandes produtoras. Uma subjetividade que se materializa sob a forma de filmes/audiovisuais que se afirmam como um "cinema menor", distribuído pelas diferentes telas e plataformas. O cinema menor não é um cinema de má qualidade ética e/ou estética, mas sim aquele produzido pelas minorias que se apropriam dos recursos técnicos do "cinema maior" dos grandes estúdios e empresas de comunicação, para poder realizar suas próprias produções. Uma prática que levou alguns cineastas e acadêmicos a dizer que "o cinema morreu”, já que é possível encontrar alguém que "faz cinema" em cada esquina.

Com a Internet, o local se torna global e o global invade a Baixada Fluminense, abrindo novas perspectivas e produzindo uma subjetividade que recusa o estigma divulgado pelos meios de comunicação sobre as marcas culturais da região: violência, miséria, carências de transporte público, de educação, saúde e segurança. A nova subjetividade se apropria das facilidades de manuseio e do barateamento de custos produzidos pela tecnologia digital, para inventar formas de criar e produzir narrativas autônomas, livres dos clichês e das palavras de ordem difundidas pelos meios de comunicação de massa. O audiovisual é a forma de expressão que domina e que mais chama a atenção na geração pós-midiática da região. Para os novos cineastas, que não têm os mesmos recursos das grandes produtoras e emissoras de TV, a linha de fuga para os grandes orçamentos foi adotar os princípios éticos e estéticos do "cinema menor".

Neste universo do "cinema menor", a precariedade dos recursos levou a formas alternativas, não só de produção, mas também de linguagens, formatos e práticas. Surgem assim audiovisuais realizados de forma não convencional, com uma força inventiva que, muitas vezes, não atende às demandas do mercado, mas possui um público cativo. São produções que expressam um "devir Baixada", que, desde o advento das redes sociais, toma conta da periferia da cidade do Rio de Janeiro.

1. A convergência tecnológica permitiu oferecer ao usuário o acesso às informações e aplicações em qualquer lugar, em qualquer rede e por qualquer canal, utilizando uma interface gráfica totalmente transparente e com excelente qualidade, agenciando os sistemas computacionais com os sistemas de telecomunicação, integrando vídeos, dados, voz e imagem. 
Por isso, enquanto seguíamos as pistas do cinema menor produzido pelos cineastas da Baixada Fluminense, levantamos as seguintes questões: as transformações tecnológicas modificaram o estatuto do cinema, mas os filmes exibidos em qualquer lugar a qualquer momento e em qualquer tela ainda podem ser chamados de cinema? O que seria o cinema menor e quais seriam os processos utilizados na produção da Baixada Fluminense? As práticas de produção utilizadas no Laboratório de Recursos Audiovisuais (Laborav) da Faculdade de Educação da Baixada Fluminense (FEBF-UERJ) estão em consonância a proposta do cinema menor produzido por uma geração pós-mídia, que abre mão das identidades prêt-à-porter?

Para responder a essas questões, tomaremos como exemplo a produção do curta-metragem de ação Zumberj, inventado e dirigido por Bruno Teles e realizado colaborativamente pelos bolsistas do Laborav, na FEBF, o campus da Universidade do Estado do Rio de Janeiro (UERJ) em Duque de Caxias. No laboratório, todos têm acesso a equipamentos profissionais, tanto de gravação de vídeo e áudio, quanto de edição, e contam com a orientação de seis bolsistas capacitados na área.

O percurso de nossa pesquisa está ligado à cartografia de territórios existenciais desenvolvida por Deleuze e Guattari, aplicadas e sistematizadas por Passos, Escossia e Kastrup. Consideramos o método da cartografia como o mais apropriado para acompanhar processos em andamento, já que não pretendemos representar o objeto pesquisado, considerado como pré-existente à pesquisa. Neste caso, o pesquisador é apenas um observador externo que cria uma hipótese que será comprovada a partir de uma análise que tem como base o conhecimento teórico e empírico já existente. Ele vai separar cada elemento do conjunto do objeto para saber o que é cada um deles para remontá-lo no final, produzindo uma nova representação. Em nosso caso, não existe objeto prévio, pois se trata do acompanhamento de um processo que se modifica de acordo com o devir dos integrantes e das condições de existência do projeto. Vamos trabalhar com os conceitos de subjetividade pós-mídia e de literatura menor de Deleuze e Guattari, que por deslizamento aplicaremos ao cinema. Além disto, tomaremos como base a bibliografia específica das áreas do cinema, tanto analógico quanto digital, das tecnologias de comunicação e informação e da convergência tecnológica.

\section{Identidades prêt-à-porter X subjetividade pós-mídia}

O filósofo italiano Maurizio Lazzarato (2004) aponta que o capitalismo contemporâneo sofreu uma enorme mudança nas formas de produção a partir do desenvolvimento 
da tecnologia digital e da convergência tecnológica. Empresa e fábrica, que funcionavam de forma integrada, voltadas para a produção de bens materiais e imateriais, se separaram. Fábricas produzem mercadorias físicas. Empresas têm uma produção imaterial: a principal é a subjetividade ${ }^{2}$. Produzem mundos e modos de vida difundidos pelos meios de comunicação que propagam palavras de ordem e clichês sob a forma de julgamentos, crenças e valores que se encarnam do consumidor como identidades prêt-à-porter que facilitam o dia a dia, produzindo certezas diante do caos cotidiano.

Trata-se de uma droga disponível em profusão no mercado da mídia, sob todas as formas e para todos os gostos: são as miragens de personagens globalizados, vencedores e invencíveis, envoltos por uma aura de incansável glamour, que habitam as etéreas ondas sonoras e visuais da mídia; personagens que parecem pairar acima das turbulências do vivo e da finitude de suas figuras (ROLNIK, 2016, p. 1)3.

Ao se "drogar" por imagens do "senso comum", o viciado em identidade procura viver e sentir sempre "o mesmo". Não existe o mundo ilimitado dos encontros que provocam o devir outro, ou seja: a possibilidade de se transformar de acordo com o encontro das forças que atuam em seu território existencial. Protegido pela estabilidade de sua identidade préfabricada, ele não é capaz de produzir o novo e de se autoproduzir nesse processo.

Ao mesmo tempo, Antoun (2008) analisa a WEB 2.0 como capaz de produzir uma nova subjetividade quando substitui o formato um-todos das mídias de massa pelo todos-todos das redes digitais. O novo formato seria mais democrático, substituindo a figura do consumidor de mídia pela do usuário capaz de criar, produzir, editar, transmitir e controlar sua própria informação. Somando a WEB 2.0 aos dispositivos móveis digitais, Rheingold (2005) detectou que a comunicação instantânea promovida pela convergência das mídias deu origem a uma "multidão esperta" (Smart Mobs / Foules Intelligents), que domina as regras dos meios de comunicação, muitas vezes subvertendo-as. A multidão esperta utiliza as tecnologias de cooperação desenvolvidas a partir da Internet para criar uma cultura alternativa, libertária e criativa, que amplia exponencialmente a produção de informação/

2. Para Guattari (1992), o indivíduo como dono de uma subjetividade de natureza industrial, maquínica, essencialmente fabricada, modelada, recebida e consumida, produzida tanto individual quanto coletivamente. Um exemplo de produção de subjetividade coletiva pela tecnologia é o aparelho celular ,que deixou de servir apenas para a comunicação entre duas pessoas para se tornar um ambiente virtual habitado pelas subjetividades.

3. Rolnik, Suely. Uma insólita viagem à subjetividade: fronteiras com a ética e a cultura. 2016. In: http:// caosmose.net/suelyrolnik/pdf/sujeticabourdieu.pdf . Acesso em: 01 nov. 2018. 
conhecimento. Ela abre mão dos direitos de autor e investe na colaboração para produzir novas formas de vida; ignora os direitos autorais e cria novas formas de produzir imagens, textos e sons. Ou seja: nova formas de pensar, agir e sentir, que Guattari denominou de subjetividade pós-mídia capaz de questionar através de suas produções as narrativas midiáticas produzidas pelas grandes empresas de comunicação (GUATTARI, 1992).

Mas enquanto a multidão esperta utiliza os recursos técnicos em busca de novas formas de vida, os viciados em identidades usam sua criatividade para reforçar seus comportamentos pré-fabricados. Com a convergência tecnológica e a popularização da banda larga no século XXI, a subcultura dos fãs, praticada apenas no mundo desde o final do século XX, ganhou um novo território. Os fãs se apropriaram dos blogs onde especulavam, criticavam, faziam sugestões, davam informações e reformulavam narrativas de seus seriados, filmes e personagens prediletos. Eles também utilizavam o processo colaborativo para criar e produzir novas histórias de seus heróis prediletos. Surgia assim uma identidade prosumidor $a^{4}$, que se apropriava da produção midiática das grandes empresas de comunicação, transformando-as, mas sem conseguir se libertar dos clichês, incapazes de apropriar da colaboração coletiva para produzir novos processos de subjetivação. O prosumidor midiático fã é um viciado em identidade; o oposto do midiativista integrante da multidão esperta, que também produz o que consome, mas que pensa no coletivo e está sempre em busca de criar um novo mundo, novas linguagens e relações.

A tecnologia digital, enquanto ferramenta, tanto para a multidão esperta quanto para os prosumidores, produziu uma subjetividade pós-mídia, que abriu um novo horizonte para a produção de filmes/audiovisuais. O cinema menor, de baixo orçamento e realizado através de formas de produção, distribuição e exibição alternativas, invadiu o mercado e provocou os debates sobre a resistência do cinema no mundo atual.

\section{O cinema morreu?}

Quando discutem sobre o fim do cinema, Gaudreault e Marion (2016) apontam que a tecnologia digital produziu continuidades e descontinuidades nas práticas cinema-

4. O termo original prosumer, habitualmente traduzido para português por prosumidor, foi criado por Toffler no seu livro A Terceira Vaga (1980) para aludir ao novo papel assumido pelo consumidor na designada era pós-moderna. De acordo com o autor, a saturação do mercado resultante da produção em massa implicaria a necessidade das empresas, para manterem os negócios rentáveis, começarem a produzir produtos e serviços personalizados, tarefa para a qual necessitavam da intervenção de um consumidor proativo, capaz de participar na delineação das características dos bens que pretendia consumir e colocar os produtores destes softce amigda por dentro e por fora atravdo os: de producao.utras nciais retornos que ele teria ao ] 
tográficas, em maior ou menor grau: na estética, na forma de produção de conteúdo, na captura e codificação da realidade, na digitalização e arquivo das imagens, na edição na distribuição das imagens para o público. Os efeitos das novas práticas provocaram verdadeiros distúrbios nos conceitos de cinema, que passam a sofrer da indecisão: a nova produção de imagens e sons seria cinema ou vídeo?

De acordo com Parente (2009), o cinema é determinado pelo suporte em película, uma câmera e um projetor numa sala escura com uma grande tela onde são projetadas imagens de luz que contam histórias, para um público coletivo. O cinema é fruto de um agenciamento de procedimentos organizacionais e protocolares associados à construção, exibição e difusão da obra cinematográfica (PARENTE, 2009). Certamente, uma parte do cinema do século XXI não segue todos estes padrões. Por isso a linha de fuga na discussão seria substituir o termo cinema pelo conceito de audiovisual.

Para identificar as condições de existência do cinema/audiovisual no contemporâneo, Gaudrault e Marion (2016) procuram continuidades e rupturas nos processos produtivos. Sobre a estética, eles apontam que não houve rupturas. No cinema comercial, ela ainda está ligada ao realismo ou à "impressão de realidade" produzida pelo dispositivo cinematográfico. De acordo com Stan (2003), em meados do século XX, realismo era uma questão que se apresentava como uma disputa ideológica. Autores como Commolli e Narboni afirmavam, sob uma visão althusseriana: "o que a câmera de fato registra é o mundo vago, não formulado, não teorizado e não refletido da ideologia dominante" (Narboni e Comolli, apud Stan, 2003, p.166). A ideia de semelhança objetiva está baseada no agenciamento entre os códigos de percepção visual do Renascimento ${ }^{5}$ à literatura clássica do século XIX. Somados às técnicas que procuravam tornar transparente os processos de produção fílmica como a edição, está o realismo cinematográfico, que predomina ainda hoje.

A continuidade também é perceptível nos formatos narrativos, que praticamente não sofreram mudanças. Mesmo com toda tecnologia, são poucas as transformações nos gêneros: ainda assistimos comédias, dramas, romances, documentários e ficções científicas, gêneros que existem desde o início do cinema, com seus "remakes". Para superar a redundância dos enredos e o esvaziamento das grandes salas, houve o grande investimento nos filmes de efeitos especiais, ou fogos de artifício (JULLIER, 1997). São eles que garantem o vigor da forma expressiva que ainda se apoia nos gêneros tradicionais, só que agora "decorados" por cenários fantásticos, pelas explosões, corridas de carro aluci-

5. Perspectiva monocular, pontos de fuga, impressão de profundidade e precisão da escala, somados aos códigos narrativos literários do século XIX (Stan, 2003, p.166). 
nadas, pessoas que se transformam em lobisomens, voos mirabolantes de helicópteros, zumbis assassinos, mágicas e, principalmente, acontecimentos fabulosos da literatura de aventuras. Entretanto, por mais alucinada que seja a fantasia, ela segue os códigos sensoriais e linguísticos que vêm de longa data e determinam o "realismo" das imagens. Como exemplo, temos a técnica de captura de movimento (mocap) das ações ou performances de atores humanos. Na captura do movimento (mocap), as informações coletadas através de sensores são utilizadas para animar personagens virtuais em três dimensões, representando de forma cada vez mais "humana" os movimentos de seres digitais.

No caso da captura das imagens pela câmera, o processo permanece o mesmo, tanto no analógico quanto no digital. As lentes "objetivas" da câmera capturam os reflexos da luz emitidos pelos referentes. Mas, na hora de reproduzir a imagem, em vez de sensibilizar uma película coberta por uma emulsão química que deve ser revelada posteriormente na técnica analógica, a imagem digital capturada é escaneada para reduzir o número de informações através da coleta de amostras e digitalizada (transformada em 0 e 1) com diferentes taxas de compressão. No digital, a imagem se transforma em linguagem, tornando-se manipulável e ocupando menos espaço nos canais de produção e distribuição. O processo de digitalização renova as possibilidades para a criação de imagens, recurso pouco utilizado, já que o objetivo final é reproduzir uma imagem o mais semelhante possível à analógica, segundo as "leis naturais".

$\mathrm{Na}$ edição, seria possível afirmar a existência de ruptura na passagem do linear para o não linear, já que a mudança técnica foi radical. No primeiro caso, o editor operava um aparelho reprodutor com uma fita de vídeo, com os planos do filme já gravados, transferindo-os para um gravador ( $\mathrm{rec}$ ) na ordem desejada. Se precisasse inserir outro plano no meio da sequência já montada, teria que refazer todo o trabalho a partir daquele ponto, porque a ordem da informação gravada (as imagens) era sequencial. Um processo trabalhoso, que gerava perda de qualidade nas imagens. Já a edição não linear permite o acesso aleatório das imagens (ramdom acess memory). Isto significa que o editor pode interferir na ordem dos planos, reduzindo-os ou ampliando-os, inserindo novos elementos ou retirando-os em qualquer ponto da timeline ${ }^{6}$. Ainda assim, na prática da edição, a ruptura técnica não foi tão radical, já que manteve a ideia da montagem transparente, onde os planos se sucedem uns aos outros (montagem horizontal) e a montagem que acumula

6. A timeline, ou linha do tempo, é a ferramenta que simula um filme com seus fotogramas, que no caso da edição digital é chamado de frame. É na timeline que são organizadas as cenas, e são modificados e/ ou acrescentados efeitos e transições), em um computador dotado de um software de edição. 
elementos em um mesmo quadro (montagem vertical) ${ }^{7}$, de forma que a transição de uma cena para outra (ou na própria cena) passe despercebida.

Mas foi na criação, no financiamento e na distribuição somados à convergência tecnológica e ao desenvolvimento e popularização da banda larga que ocorreu a grande ruptura cinematográfica. De acordo com Alvez (2014), com a Internet, a convergência das mídias e das redes sociais emergiu um agenciamento entre conhecimentos artísticos e técnicos da equipe reunida on-line, que passou a permitir a criação colaborativa, questionando assim a ideia de autor, tão cara aos teóricos de cinema e realizadores dos anos 1950/60.

$\mathrm{Na}$ verdade, o cinema sempre foi colaborativo e, ao mesmo tempo, cooperativo. Na realização dos filmes, todos cooperam e colaboram durante a produção, realizando as tarefas para as quais foram indicados. A colaboração atual, entretanto, pode ser de todos, em todas as fases, desde a criação até a definição de práticas e tarefas. Roteiro, cronogramas, orçamentos, planos de gravação e financiamento para produção e distribuição etc. Alvez (2017) define o cinema colaborativo do século XXI como "o processo de produção cinemática resultante da colaboração entre múltiplos intervenientes ligados através da WEB. Esta colaboração supõe não a mera justaposição de contributos, mas efetiva, de vários agentes na construção de um objeto único" (ALVES, 2017, p. 146). A colaboração na criação está ligada à contribuição artística e técnica de vários participantes em rede. Já o financiamento ${ }^{8}$ ocorre a partir de doações em dinheiro através de plataformas especializadas, que vão permitir a realização do projeto (ALVEZ, 2014). Estas são algumas permanências e "quase" rupturas que nos levam a aplicar o conceito de audiovisual. Mas se houve uma ruptura promovida introdução da tecnologia digital no universo do audiovisual digital, ela está na produção da subjetividade pós-mídia, onde se colocam novos padrões de criação, fruição, produção e distribuição por canais de circulação que provocaram novas formas de pensar, agir e sentir em sintonia com o século XXI. De acordo com Gaudreault e Marion (2016) seus efeitos foram uma mudança radical na forma de produção cinematográfica que levou alguns cineastas a dizerem que o cinema nunca esteve tão vivo

7. Os dois processos foram teorizados por Eisenstein, ainda nos anos 1940. Para Eisenstein, a própria criação do plano já era uma edição, onde os elementos de cena eram "montados" no próprio quadro (montagem vertical), com cenários, personagens, texturas etc. Na montagem vertical digital, não é necessário reproduzir referentes como cenários, texturas e objetos. Eles são realizados numericamente e incrustrados nos planos digitalmente.

8. Luz relata que, em 2012, o relatório sobre financiamento do Crowdsourcing.org, apontava que existiam 452 plataformas online oferecendo este serviço, a maior parte na Europa e nos Estados Unidos. Em 2011, foram angariados cerca de 1,2 bilhões de euros para financiar um milhão de projetos. 
Entretanto, podemos apontar que a maior parte destas transformações não se materializa em novas formas éticas e estéticas inventivas ou surpreendentes. Uma pesquisa na plataforma de distribuição de vídeos em streaming Youtube mostra que os equipamentos de baixo custo com funcionamento intuitivo e a convergência das mídias permitiram o surgimento de novos cineastas, que repetem as mesmas fórmulas ou clichês presentes nos filmes de ficção, comerciais, documentários, curtas-metragens e programas de televisão. No YouTube é possível acessar desde os filmes com imagens de celular até os grandes clássicos e superproduções do cinema; desde 2012 é um aplicativo para telefones celulares com alcance global'; tem cerca de um bilhão de usuários, equivalente a um terço de toda Internet; a maioria dos acessos se dá pelos dispositivos móveis; no Brasil, tem mais de 82 milhões de usuários ${ }^{10}$ e é a principal forma de acesso dos jovens da periferia aos filmes, vídeos, tutoriais de gravação, edição e recursos como os demonstrativos e tutoriais de softwares de efeitos visuais que podem ser utilizados por todos.

\section{Do "cinemão" ao cinema menor}

No século XXI, os filmes realizados pelos grandes estúdios com altos orçamentos convivem com filmes e vídeos de baixo orçamento, que não são exibidos nos canais comerciais de TVs e nas grandes salas de cinema, mas que estão presentes em cineclubes e canais de streaming na Internet e nas plataformas de redes sociais. Eles fazem parte de uma categoria que pode ser chamada de "cinema menor", conceito que surge a partir do deslizamento do conceito de "literatura menor" desenvolvido por Gilles Deleuze e Felix Guattari (2014).

A literatura menor não se refere a uma escrita de pouca qualidade ou a uma língua minoritária: "uma literatura menor não é a de uma língua menor, mas antes a que uma minoria faz em uma língua maior” (Deleuze; Guattari. 2014, p.35). A literatura menor se apropria dos agenciamentos da literatura maior, desterritorializando-os a partir dos agenciamentos que provoca. Isso acontece quando as minorias desterritorializadas são incapazes de se apropriar plenamente da língua maior, criando sentidos para as palavras existentes e produzindo uma nova língua que é a mesma/diferente e que pode até se transformar em um dialeto. Neste caso, uma literatura menor garante sua diferença quando evita ser domesticada pelos gêneros de literatura maior, podendo deslizar por todos eles.

9. https://www.youtube.com/intl/pt-BR/yt/about/press/ - acessado em 30/11/2017.

10. http://tecnologia.ig.com.br/2016-10-05/youtube-usuarios.html. 
Sua característica é ser essencialmente política, baseada em casos de indivíduos que sofrem com a pressão das forças naturais e sociais, que estão sempre em primeiro plano. Forças como o Estado e as leis que atuam controlando e determinado a vida da comunidade que, por sua vez, submete o indivíduo. Em Kafka, autor ícone da literatura menor, personagens se dissolvem diante das forças externas quando lutam por se firmar em seu pequeno território. Nas narrativas da literatura maior, os grandes meios sociais são apenas o pano de fundo para as aventuras do herói, que está sempre em primeiro plano. O importante são seus duelos, contra o meio, a sociedade e contra si mesmo, como nas histórias dos super-heróis. Ele está sempre em busca de recompor a situação inicial, conturbada por algum problema externos, como uma invasão intergaláctica ou dos zumbis mortos-vivos. Outra característica da literatura menor está ligada às enunciações, que não são realizadas por um indivíduo solitário, o autor, que se apropria da língua maior, utilizando-a para consolidar a consciência coletiva nacional que sempre corre o risco de se desagregar e que é salva pelo herói. O escritor da literatura menor, como é aquele que está sempre na periferia, procura exprimir uma outra comunidade, busca os meios para produzir novas subjetividades, novas consciências e sensibilidades. Em resumo:

[...] as três características da literatura menor são: a desterritorialização da língua, a ligação do individual no imediato-político, o agenciamento coletivo da enunciação. É o mesmo que dizer que 'menor' não qualifica mais certas literaturas, mas as condições revolucionárias de toda literatura no seio daquela que se chama grande (ou estabelecida)" (DELEUZE; GUATARRI, 2014, p. 39).

Deslizando o conceito de literatura menor, podemos definir três características para o "cinema menor": desterritorializar as relações entre sons, imagens e tecnologia desenvolvidas pelo cinema maior, criando novas formas de conteúdo e de expressão, bem como novas formas éticas e estéticas que se configuram como uma marca territorial cultural; ser essencialmente político, abrindo mão das grandes narrativas, para se focar nos casos de "pequenos" indivíduos em suas lutas contra o meio ambiente, contra a sociedade e contra a marginalização e o estigma; utilizar os agenciamentos coletivos e colaborativos de enunciação e de produção para viabilizar projetos, tanto na tecnologia, quanto na forma e no conteúdo.

Neste contexto, o cinema menor é capaz de revolucionar "de dentro" as condições de realização cinematográficas, transformando processos, produtos e gerando novas subjeti- 
vidades. A literatura menor garante sua diferença quando evita ser domesticada pelos gêneros de literatura maior, podendo deslizar por todos eles. O mesmo acontece com o "cinema menor" que, ao se apropriar dos recursos tecnológicos para inventar novos sons e imagens, renova o cinema na era do digital, materializando um efeito da subjetividade pós-mídia.

\section{Zumberj: práticas inventivas para produzir um cinema menor}

Nas duas primeiras décadas do século XXI, a universalização do acesso à internet, o surgimento dos sites de armazenamento de blogs, vídeos e fotos e o barateamento do das ferramentas digitais, tornaram todas as etapas da cadeia da produção cultural acessíveis às pessoas de periferia. Os produtores da Baixada Fluminense imediatamente se apropriaram das novas ferramentas e criaram coletivos como o Enraizados, Angu TV, Buraco Cavernoso e Lurdinha, entre outros, onde expressavam e divulgavam as marcas territoriais da Baixada através da música, de personagens de comédias e seriados, de transmissões ao vivo (streaming), criação de games, produção de vídeos e de cartografias. A rede permitiu a mobilização de grupos de interesse que passaram a criar eventos como a Cypher (street dance), as batalhas de DJ, as feiras de troca de livros, os saraus literários e os eventos internacionais de grafitti como o MOF (Moving of Favela). Surgia assim uma nova realidade sociocultural, com orgulho da expressão de suas marcas culturais, que saíam do "gueto".

No universo do "cinema menor" da periferia do Rio de Janeiro, a precariedade dos recursos levou a alternativas não só de produção, mas também de linguagens, formatos e práticas. Por exemplo, em uma produção tradicional, geralmente parte-se de uma ideia para daí projetarem-se os efeitos. Esse procedimento demanda muito tempo e esforço humano, o que acaba inviabilizando produções de baixo ou quase nenhum orçamento. Surgem assim os vídeos realizados de forma não-convencional mas com força inventiva que não dependem do mercado de trabalho nem das produtoras de vídeo profissionais.

Neste contexto, Zumberj se insere na categoria de "cinema menor". A proposta de produção do audiovisual em uma faculdade de educação vai além do uso das tecnologias como ferramenta acessória de aprendizagem e procura inserir os futuros professores no universo criativo da subjetividade pós-mídia da multidão esperta prosumidora. Zumberj está sendo realizado na CPMK, a Central de Produção Multimídia Kaxinawá na FEBF, que engloba o Laborav (Laboratório de Recursos Audiovisuais), que funciona como uma produtora de vídeos de ficção, didáticos, documentários e séries para televisão, juntamen- 
te com um estúdio de áudio equipado e uma rádio comunitária, além de laboratório de informática com 20 computadores com hardwares e softwares atualizados. Conta também com bolsistas pesquisadores e artistas voluntários oriundos da comunidade do entorno, que utilizam os equipamentos e participam de todas as produções realizadas a partir dos projetos de extensão realizados pela CPMK e pelo Laborav.

O projeto do curta metragem Zumberj partiu de Bruno Teles, um desses artistas da comunidade. A criação de um vídeo de ação no formato dos blockbusters do cinema americano de ação e terror era um desafio para os jovens bolsistas acostumados a registrar os eventos da faculdade, os documentários antropológicos, as entrevistas com cientistas e as matérias jornalísticas ligadas aos conteúdos das disciplinas. O enredo de Zumberj gira em torno de dois jovens rebeldes que procuram sobreviver em meio à infestação de zumbis em um cenário pós-apocalíptico. Eles têm que chegar a um determinado local para serem resgatados por um helicóptero. No caminho, precisam vencer diversos obstáculos, incluindo os zumbis, para atingir o seu objetivo. O mocinho, Bruno, é o chefe dos rebeldes e tem uma namorada loira de cabelos compridos e vestida com uma roupa colante negra. É sexy e violenta. $\mathrm{O}$ antagonista, uma espécie de zumbi chefe, é um cientista que procurava encontrar uma fórmula contra a contaminação provocada pelos zumbis. Por acidente, a fórmula é injetada em seu corpo e ele adquire poderes especiais que o tornam, inclusive, capaz de controlar os zumbis.

Zumberj é uma experiência de produção sui generis: uma ficção científica realizada em uma Faculdade de Educação por futuros professores, de forma colaborativa, a partir da apropriação de tutoriais de softwares de efeitos visuais disponíveis gratuitamente na Internet. Os tutoriais reproduzem as principais cenas dos blockbusters de ação, como os filmes de mercenários e de super-heróis: figuras em 3D de zumbis, helicópteros, aviões, armas, lutas e explosões, que hoje fazem parte do universo cultural de qualquer jovem fã de ficção científica. Para criar uma cena de explosão ou de alguém pendurado em um helicóptero em pleno voo, basta incorporar o efeito pré-fabricado disponibilizado na rede ao material filmado pelo prosumidor. Uma solução inventiva para driblar os altos custos das grandes produções cinematográficas.

Entretanto, a criatividade de Bruno no processo de produção, ao se apropriar de recursos técnicos da Internet, não se refletiu na forma de suas imagens e nem no conteúdo de sua narrativa: a maior parte das cenas reproduzem em detalhes a estética, o ritmo e o clima dos filmes de ação clichês produzidos em Hollywood. Principalmente com o uso da violência e das armas como uma forma de solução dos desafios que surgem ao longo da 
história. Identificamos, neste momento, a influência das identidades pret-à-porter baseadas nos clichês midiáticos as quais se refere Rolnik (2016).

Ao mesmo tempo, como um efeito das práticas aplicadas no Laborav, as próprias etapas de produção foram subvertidas. Normalmente parte-se de um roteiro para daí projetarem-se os efeitos visuais, que irão se moldar à narrativa. Zumberj inverteu o processo: foram os planos recheados por efeitos especiais que deram o pontapé inicial. Depois vieram as cenas captadas nos arredores da FEBF, onde os efeitos foram incrustados. Tais experimentações fizeram com que a narrativa começasse a se delinear. Desse modo, os jovens que atuam no Laborav mostram que estão em sintonia com o conceito de multidão esperta, capaz de se apropriar de forma criativa dos recursos da cultura mercadoria.

Ao mesmo tempo, Zumberj se alinha com os filmes de fãs, já que histórias de zumbis estão presentes as narrativas predominantes que se encontram na "cultura jovem" dos jogos eletrônicos e seriados, territorializando-as de acordo com as marcas territoriais da Baixada Fluminense em termos de locações. A precariedade de produção também implicou em elementos narrativos sui generis. Deste modo, Zumberj surge como um misto da materialização da subjetividade pós-mídia e das identidades prêt-à-porter entre os alunos da FEBF, se configurando como um produto do cinema menor, a partir de um deslizamento das narrativas e modos de produção do cinema maior contemporâneo.

\section{Algumas considerações}

É impossível dissociar a produção do Zumberj do território da Baixada Fluminense onde está localizada a FEBF. A faculdade, ainda que pertença à Universidade do Estado do Rio de Janeiro (UERJ), possui uma singularidade atravessada pela condição periférica de seu território, onde os processos de territorialização e desterritorialização são constantes. A periferia tem uma enorme capacidade de se apropriar e territorializar o exterior, sempre produzindo novas formas de pensar, agir e sentir.

Longe de representar um dado negativo, essa abertura é o campo de potencias de onde surgem soluções inventivas para novos problemas que se apresentam no cotidiano carente. A tecnologia digital, por sua vez, é a linha de fuga que desterritorializa e amplifica as potencialidades inventivas no campo artístico, abrindo espaço para novas produções de conteúdo típicos do "cinema menor" características da subjetividade pós mídia.

Citamos Zumberj como exemplo de uma das formas colaborativas de produzir conteúdo para uma TV Menor, além de promover a interface entre arte, tecnologia e 
educação em uma sociedade na qual predomina uma subjetividade pós-mídia. Produzir conteúdos para uma TV Menor é uma prática que exprime a potência artística excluída dos circuitos intelectuais onde predomina a cultura-valor, mas que em momento algum deixa de estar presente no cotidiano das artes "menores" das populações periféricas. Uma consequência da precariedade que leva à busca por novos modos de produção e que obriga ao uso constante da criatividade e da invenção como um recurso para a sobrevivência.

\section{Referências}

ALVEZ, Marta Pinho. Cinema 2.0: Modalidades de produção cinemática no tempo do digital. Covilhã,Portugal. Ed. LavCom.IFP. 2017. Disponível em http://www.labcom-ifp.ubi.pt/ficheiros/201711091353-201711_cinema20_mpalves.pdf. Acesso em: 07 jun. 2018.

ANTOUN, Henrique (org.). WEB 2.0. Participação e vigilância na era da comunicação distribuída. Rio de Janeiro; Ed. Mauad X. 2008.

DELEUZE, Gilles. A Imagem movimento. São Paulo: Ed. Brasiliense, 1990.

DELEUZE, Gilles. Proust e os signos. São Paulo: Ed. Forense, 2003.

DELEUZE, Gilles; GUATTARI, Felix. Mil Platôs: capitalismo e esquizofrenia. Vol.2. Rio de Janeiro: Ed.34, 1995.

DELEUZE, Gilles; GUATTARI, Felix. Mil Platôs: capitalismo e esquizofrenia. Vol.4. Rio de Janeiro: Ed.34, 1997.

DELEUZE, Gilles; GUATTARI, Felix. Kafka: por uma literatura menor. Belo Horizonte: Autêntica Editora, 2014.

GUDREAULT, André; MARION, Philippe. O fim do cinema? Uma mídia em crise na era digital. Campinas, SP: Papirus, 2016.

GUATTARI, Félix. Caosmose. Rio de Janeiro: Ed. 34, 1992

GUATTARI, Félix; ROLNIK, Suely. Micropolíticas: cartografias do desejo. Rio de Janeiro: Vozes, 2005. 
HAMUS-VALLÉE, Réjane. Retours vers le passé: images de synthèse et cinema. Cahiers du Cinema, Paris, Hors Serie, 1999.

HAMUS-VALLÉE, Réjane. Les effets speciaux. Paris: Ed Cahiers du Cinéma, 2004.

JENKINS, Henry. Cultura da Convergência. São Paulo: Editora Aleph Ltda., 2006.

JENKINS, Henry. Invasores do texto: fãs e cultura participativa. Nova Iguaçu, RJ” Marsupial Editora, 2015.

JULLIER, Laurente. L'écran post-moderne: un cinema de l'allusion et du feu d'artifice. Paris :L’Harmattan, 1997.

KASTRUP, Virginia. $A$ invenção de si e do mundo: uma introdução do tempo e do coletivo no estudo da cognição. Belo Horizonte: Autêntica, 2007.

KASTRUP, Virginia. Aprendizagem, arte e invenção. Psicologia em Estudo, Maringá, v. 6, n. 1, p. 17-27, jan./jun. 2001.

LAZZARATO, Maurizio. Creer des mondes: capitalisme contemporain et guerres esthetiques In: Multitudes 15. Art Contemporain La recherché du dehors. Paris, hiver. 2004 Disponível em https://www.cairn.info/revue-multitudes-2004-1-page-229.htm. Ultimo acesso em 30/09/2017.

OLIVEIRA, Bernardo Simbalista. Zumberj: Cinema, Tecnologia e Invenção na Faculdade de Educação da Baixada Fluminense. Dissertação. Duque de Caxias, RJ: Faculdade de Educação da Baixada Fluminense/UERJ. 2017.

RECUERRO, Raquel. Problematizando fãs e fan fictions 20 anos depois. In: JENKINS, Henry. Invasores do texto: fãs e cultura participativa. Nova Iguaçu, RJ: Marsupial Editora, 2015.

RHEINGOLD, Howard. Foules inteligentes: la revolution qui commence. Paris: Éditions M2, 2005.

ROLNIK, Sueli. Subjetividade antropofágica. In: DOMINGUES MACHADO, Leila; CAMPELO, Maria Cristina; DE BARROS, Maria Elizabeth (org.). Texturas da psicologia, subjetividade e política no contemporâneo. São Paulo: Casa do Psicólogo, 2002.P.11-2. Disponível em: http://www.pucsp.br/nucleodesubjetividade/Textos/SUELY/Subjantropof.pdf._Acesso em: 01 nov. 2016. 
ROLNIK, Sueli. Toxicômanos de identidade: subjetividade em tempo de globalização. In: LINS, Daniel (org.). Cultura e subjetividade: saberes nômades. Campinas: Papirus, 1997. p. 19-24. Disponível em: http://www.pucsp.br/nucleodesubjetividade/Textos/SUELY/Subjantropof.pdf. Acesso em: 01 nov. 2016.

ROLNIK, Sueli. Novas tecnologias e as narrativas sensoriais no cinema do século XXI: filmes de ação de Hong Kong e Hollywood. Tese (Doutorado em Comunicação e Cultura)- Escola de Comunicação, Universidade Federal do Rio de Janeiro, 2006.

SÁ REGO, Alita. Experimentando teorias e práticas inventivas na aprendizagem da produção audiovisual. In: NAGAMI, Eliane (org.). Processos educativos na interface Educação e Comunicação. Ilheus, BA: Editus,2016

STAN, Robert. Introdução à teoraia do cinema. Campinas, SP: Papirus. 2003. 